\title{
Discursive Frameworks for the Development of Inclusive Robotics
}

\author{
Manuel Aparicio, Mario Toboso, Txetxu Ausín, Daniel López, Ricardo Morte and Aníbal Monasterio
}

\begin{abstract}
Important ethical-political ideas are analysed in this contribution: autonomy, dependency, vulnerability, functioning, care and disability, within the relevant discursive frameworks for development of an inclusive robotics. This development will have to take into account the regulatory framework of the UN Convention on the Rights of Persons with Disabilities, and prospectively orient itself towards facilitating autonomy in the achievement of human functionings in inclusive environments, guaranteeing the conditions for good care. To this end, it will be important to also pay attention to theoretical frameworks such as the capability approach (Sen, Nussbaum) and ethical conceptions of care (Tronto, Kittay). Additionally, we feel another social group that should be considered regarding the consequences coming from the introduction of robotics is the group made up of children and adolescents. For the responsible integration of inclusive and interactive robotics, as a mediating factor in the socialisation process, it is necessary to maintain careful protections in regard to the inherent vulnerability of this group; this requires that the general regulatory obligations regarding protection, full development and wellbeing underlying the discourse in the Convention on the Rights of the Child be used as a reference in order to always safeguard the greater interests of the minor.
\end{abstract}

\section{INTRODUCTION}

$\mathrm{M}$ ore than mere instruments, robotic artefacts are mediations arising from a certain socio-cultural context and which open up new possibilities in human functioning, having transformative potential over this context. Interactive robots incorporate values coming from the different social agents involved in their design, manufacture and use. Each agent may have their own discourse in regard to their possible benefits or harm. Confrontation between different discourses by means of inclusive public debates constitutes a necessity [1], [2] so that the introduction of interactive robots in society favours wellbeing and justice.

These two aspects, along with quality of life, make up the triad upon which the functionings and capabilities approach

This paper benefits from Grant Agreements 780073-INBOTS and 779982-EXTEND.

M. Aparicio is an Associate Professor at the University of Murcia, Murcia, Spain (manuel.aparicio@um.es).

M. Toboso is a Tenured Scientist at the Department of Science, Technology and Society in the Institute of Philosophy of the Spanish National Research Council, Madrid, Spain (mario.toboso@csic.es).

T. Ausín is a Tenured Scientist at the Department of Theoretical and Practical Philosophy in the Institute of Philosophy of the Spanish National Research Council, Madrid, Spain (txetxu.ausin@cchs.csic.es).

D. López is a Predoctoral Researcher at the Department of Theoretical and Practical Philosophy in the Institute of Philosophy of the Spanish National Research Council, Madrid, Spain (daniel.lopez@csic.es).

R. Morte is a Ph.D. Student at the University of Granada, Granada, Spain (ricardo63@autistici.org).

A. Monasterio is a Basque Government Posdoctoral Researcher, Bilbao, Spain (anibal.monasterio@ehu.eus).

They constitute the IFS-CSIC Research Group in INBOTS and EXTEND projects. from Amartya Sen and Martha Nussbaum is based [3]. The most basic idea in this approach are the "functionings," such as activities, personal or social, in their broadest sense, or states of being, whose achievement we value as important for our wellbeing and quality of life. Today, numerous functionings are mediated by robotic devices. Think about, for example, the environment in which people who are dependent, children, the elderly or those with disabilities are cared for. In this particular environment, for varying reasons, the introduction of such devices are encouraged as a substitute for traditional human care [4]. Nevertheless, resorting to these devices should not be a source of new discrimination regarding access to basic care and attention, and should indeed, however, contribute to a "democratization of care," in the words of Joan Tronto [5], that also overcomes the enormous gender bias that has befallen this fundamental activity for social reproduction [6].

The introduction of robotic devices in domestic environments or institutional ones (schools, hospitals, etc.) must be done in such a way that the overall dimensions of the care offered to create, consolidate and support personal autonomy contribute to good development of human beings in all their different life stages. This introduction should take into account that the technologically-mediated interpersonal relationship ("human being-robotic artifact-human being" relationship) or the "human being-robotic artifact" relationship is produced in a social context in which the priority is to guarantee security, mental and physical integrity, emotional stability and respect for the dignity of the person [7], [8].

\section{MATERIAL AND METHODS}

These are the conceptual and normative materials that serve as the foundation for our reflections. On the one hand, the Convention on the Rights of Persons with Disabilities (CRPD), as well as the Convention on the Rights of the Child (CRC), as regulatory frameworks with international validity. On the other, Sen and Nussbaum's capability approach constitutes a widely-accepted and influential ethical-political paradigm, just as the theories of Tronto and Kittay do in the field of care.

The methods used are philosophical: analytical reading of the selected bibliography; conceptual analysis of ideas related to care; philosophical-practical reflection on care and its quality.

\section{RESULTS}

The CRPD and the $\mathrm{CRC}$ are international regulatory frameworks having legal repercussions in the majority of countries in the world, without forgetting that as modulations in universal human rights, they also imply 
ethical requirements [9] that are indispensable in different professions [10]. To advance responsibly in a model for interactive inclusive robotics, in terms of wellbeing and justice, the professionals involved in their development must receive training in these judicial-moral documentst, given the importance socio-technical mediations have for full enjoyment of human rights [11].

In addition to its regulatory dimension, the underlying theoretical discourse in the CRPD is important which, based on the social model of disability, interprets this as a social construction produced by the interaction between people with diverse bodily or mental functionings and exclusionary social structures [12]. The social model substitutes for the traditional medical-rehabilitation model, which restricts the disability to the individual sphere, by conversely trying to eliminate all barriers: physical, regulatory, political, economic, social, cultural or attitudinal that affect people with disabilities. Neither current developments in assistential robotics nor the majority of reflections on robo-ethics sufficiently take these questions into account, nor do they expressly refer to the CRPD [1], [2].

With respect to the values in the CRPD to be taken into account in developing robotics, we point out the following: 1) Respect for every type of human functional diversity. Robotic care must deal with the wide diversity of human functionings. 2) Inclusion requires universal accessibility and universal design. Robots and robotic environments must be accessible and promote, in addition to health, social inclusion. 3) Social participation of people receiving assistance demands having a voice in all the phases of development and implementation of robotics.

The change in discourse the CRPD has brought about allows the idea of care (or assistance) and other related ideas (vulnerability, autonomy, dependency) to be redefined. Care is now conceived as a right that is, in turn, reinforced by the set of rights in this Convention and by technological mediation. Thus what is stressed is a "public" vision of care, as opposed to another that is benevolent and with an enormous gender bias. There is also more awareness now that physical or mental vulnerability interacts with the social vulnerability resulting from stigmatization and from the discriminatory configuration of the socio-technological environment [13]. Limitations on personal autonomy in dependent people are no longer conceived as destiny or as an inherent quality in these limitations, but rather as a contextual condition that can be modified or is subject to attention in the framework of human rights. Nor is dependency, as a situation that requires care, conceived apart from the possibility of an independent life.

Something similar happens in the case of the social group made up of children and adolescents. Structural changes that have taken place in Western families since the middle of the twentieth century have led to a redefinition of care to make it compatible with the understanding of children and adolescents as human beings who are in a growth process in regard to exercising their own autonomy [14], [15]. This transformation has implied that the main role given to parents today consists in accompanying their children emotionally and keeping them safe during a complex process to progressively gain independence. This conception of childhood and adolescence as relevant stages in personal maturation is clearly reflected in the policy implications in the CRC: the right to the necessary protection and assistance for their wellbeing, right to harmonious development of their personality in a family environment, etc.

Future developments in robotics will have to be consistent with this conception, and with the policy guidelines arising from the set of rights established in the CRC. Supervision of the prospective processes to design, build and evaluate robotic devices aimed at children and adolescents, generally more inclined towards an uncritical "technological fetishism," must be done from an ethical-legal principal focused on the best interests of the minors. These interests will be respected if, with such devices, any harm to the minors' abilities and personalities are avoided, subject to a progressive training process (the principle of nonmaleficence); if it is ensured that benefits will include comprehensive training of the personality and wellbeing (the principle of beneficence); if the minors' autonomy is progressively encouraged to make them capable of having self-control over their lives in a robotised socio-technical context (principle of autonomy); and if equality in access to robotic devices responding to such principles is fostered (principle of justice).

Accordingly, we think that inclusive robotics must conform to an axiological framework characterised by: a) security, which implies the construction of robots that are safe and collaborate in protecting life, physical and mental integrity, and the privacy of children and adolescents; b) graduality: the design and construction of robots must adapt to the evolution of the physical and psychological characteristics produced in each stage of life, and c) respect for development of the personality: implementation of robotics must be respectful of the complete and harmonic development of the cognitive, emotional and moral dimensions that make up the developing personality of children and adolescents.

Altogether, some implications of this conceptual redefinition for assistential robotics are: 1) It needs to contribute to improving the social task of care-giving; 2) It needs to facilitate the autonomy of people receiving assistance in the social environments in which they develop; 3) It needs to form part of the socio-technological foundation that supports their rights as a whole.

\section{Discussion}

The implementation of a truly inclusive robotics that interacts with humans should take into account the regulatory aspects of the CRPD and the CRC, and prospectively orient itself towards facilitating autonomy in the usual environments for activity and social participation. 
Additionally, it should guarantee the conditions for good care.

A very important aspect of the capabilities approach connects with one of the Principles of the CRPD (art. 3.d): respect for difference and acceptance of persons with disabilities as part of human diversity and humanity. In this approach, special attention is paid to the intrinsic diversity of people as the possible origin of inequalities. This express attention to personal diversity can, by the same token, be transferred to the way of achieving the different functionings [16]. A person with tetraplegia who gets around in a wheelchair and another person who walks achieve the same functioning, to move around, and both ways should have the same probability of fulfilment. What happens, nevertheless, is that the presence of architectural barriers in numerous environments often limits how the person in a wheelchair moves around.

Attention to diversity in the attainment of functionings comes under the concept of "functional diversity," proposed in 2005 within the Independent Living Movement in Spain [17]. This concept is closely related to the capabilities approach [13]. Returning to the example of the person with tetraplegia, we would say that the architectural barriers socially situates them as a person who is discriminated against because of their functional diversity. But in addition to architectural barriers, many others exist that in the same way affect the achievement of valuable functionings in different environments. If the introduction of robotic devices in functionings environments brings with it barriers or discrimination regarding access, you cannot speak of a robotics that is truly inclusive.

In regard to the social group made up of children and adolescents, the CRC establishes in Article 23 that their education must be directed towards maximum development of physical and mental capacities, development of the personality and the assumption of a responsible and unprejudiced life. Accordingly, robotic artifacts must be programmed in such a way that they can reinforce this designated direction in education. The objective of incorporating these technological devices in educational processes will be to contribute to stimulating the different capabilities; they must also be monitored, as their continued use may actually lead to undermining these same capabilities. It is also necessary to take into account that the use of robots does not negatively interfere in the shaping of the personality, with the consequent loss of self-esteem, and that this use does not facilitate the acquisition of prejudices due to the existence of biases in their programming.

For the first time, in Article 24, the CRPD explicitly states that the right to an education is the right to an inclusive, quality education, recognising the right to an education without discrimination and on the basis of equal opportunities within an inclusive educational system for people with disabilities.

With the aim of promoting their full participation and on equal terms in education and as members of the community, pertinent and personalised measures with reasonable accommodations and support should be adopted for full social inclusion (facilitating the learning of Braille, alternative writing, and orientation and mobility skills; learning of sign language and encouragement of linguistic identity for deaf people; appropriate augmentative and alternative means and formats of communication; and educational techniques and materials to support disabled students, etc.).

The realisation of many of these measures is based on technological devices and, foreseeably in the short term, robotics. To avoid a "robotic divide," it will be necessary to pay close attention to the requirements for access to devices in relation to students with disabilities. It should be kept in mind that universal accessibility (Article 9 of the CRPD) constitutes a fundamental right of persons with disabilities as it is the axis upon which rests fulfilment of many other rights, such as the right to inclusive education. It is also timely to point out that although universal accessibility and reasonable accommodations are demands coming from a minority group of students with disabilities, these could benefit a majority of users in the educational environment. Actions to make demands and implement them transform not only this environment but also the social one, and this results in benefits for many other users. As such, these actions should be considered examples of social innovations and even, depending on their techno-scientific character, could represent cases of Responsible Research and Innovation within the RRI paradigm.

\section{ConClusions}

This contribution emphasizes the importance of developments in interactive robotics taking into account the discursive approach and regulatory principles of the Convention on the Rights of the Child as well as the Convention on the Rights of Persons with Disabilities, which should be known by the designers and manufacturers of robotic devices.

The rights of children and adolescents must constitute an indispensable reference for an interactive robotics that can be used for the purpose of collaborating with families and institutions in the good care and harmonious construction of the full autonomy that children and adolescents need to progress in their ongoing process of personal maturation.

Awareness on the rights of the disabled (applicable also to rights for the elderly) can favour reorientation of interactive robotics towards objectives that are not only focused on care and rehabilitation, promoting greater human development in more inclusive social environments [13]. The possibility of inclusive environments for care having a social nature requires that the diversity of functionings be valued socially, some of which will involve technological and, especially, robotic mediation. In this way, discourse on functional diversity places the need for care implied in natural human vulnerability within an inclusive social perspective. 


\section{REFERENCES}

[1] Unesco, "Report of COMEST on robotics ethics", 2017

[2] European Group on Ethics in Science and New Technologies, "Artificial Intelligence, Robotics and 'Autonomous' Systems", Luxembourg: Publications Office of the European Union, 2018.

[3] M. C. Nussbaum \& A. Sen (Eds.), The quality of life, New York: Oxford University Press, 1993.

[4] A. Ortega, La imparable marcha de los robots, Madrid: Alianza Editorial, 2016.

[5] J. Tronto, Caring Democracy. Markets, Equality, and Justice, New York University Press, 2013.

[6] E. F. Kittay, Love's Labor: Essays on Women, Equality, and Dependency, Nueva York, Routledge, 1999.

[7] Convention on the Rights of Persons with Disabilities. New York, $\mathrm{UN}, 2006$.

[8] Convention on the Rights of the Child, New York, UN, 1989.

[9] J. Habermas, "El concepto de dignidad humana y la utopía realista de los derechos humanos" en La constitución de Europa, Madrid: Trotta, 2012.

[10] A. Cortina, Ciudadanos del mundo. Hacia una teoría de la ciudadanía, Madrid: Alianza Editorial, 2005]

[11] L. Winner, "Is there a right to shape technology?", Argumentos de Razón Técnica, $\mathrm{n}^{\circ} 10,2007$, pp. 305-328.

[12] A. Palacios, El modelo social de la discapacidad: orígenes, caracterización y plasmación en la Convención Internacional sobre los Derechos de las Personas con Discapacidad, Madrid: Ediciones Cinca, 2008.

[13] M. Nussbaum, Las fronteras de la justicia, Barcelona: Paidós, 2007.

[14] A. Honneth, El derecho de la libertad. Esbozo de una eticidad democrática. Madrid: Katz, 2014.

[15] L. Rojas Marcos, Convivir. El laberinto de las relaciones de pareja, familiares y laborales, Madrid, Aguilar, 2008.

[16] M. Toboso, "Rethinking disability in Amartya Sen's approach: ICT and equality of opportunity", Ethics and Information Technology, 13(2), 2010, pp. 107-118.

[17] J. Romañach y M. Lobato, "Functional diversity. A new term in the struggle for dignity in the diversity of the human being", Foro de Vida Independiente y Divertad (Spain), 2005.

https://disability-studies.leeds.ac.uk/library/ 